\title{
Peripheral Realities: Visual Artists in Cebu, Philippines
}

\author{
Dennis E. Montera \\ University of the Philippines Cebu, Cebu City, Philippines \\ National Cheng Kung University, Tainan City, Taiwan \\ Hui-Wen Lin \\ National Cheng Kung University, Tainan City, Taiwan
}

\begin{abstract}
Visual artists in the island provinces of the Philippines often find themselves navigating through adversities in the production and dissemination of their creative work. With the visual-arts praxis being exclusively cited in the nation's capital city, the majority of artists spread over an archipelago of seven thousand islands fall under the notion of struggling, but persevering creator. This paper aims to describe and evaluate the art ecology of Cebu City, the art-related conditions of artists and their tenacity. The methodology used for case-creation: semi-structured interviews, in-depth interviews, and observation. The main finding of the study is that contemporary visual artists in the island province of Cebu, Philippines perceive the struggles from the production to the consumption of art as customary to their milieus. The study plots the current visual-arts ecology model of the locale and proposes future innovations for the development of the sector's value chain. From the context of a developing country, the study also expands the discussion between creating art for art's sake and art as a market commodity through the intermediate position of artists.
\end{abstract}

Keywords: artists, art eco-system, identity, artist-related factors

\section{Introduction}

Developing a city's visual arts should be given importance because of its spilling effects to other sectors (Bilton, 2010; Klamer, 1996; Abbings, 2002). Nevertheless, art in cities like Cebu seems relegated to happenstance as society evolves. This leads to the concept of peripherality which refers to the marginalization of the locale in relation to metropolitan cities and first-tier capital cities. This marginalization vis-à-vis the art center challenges both art entrepreneurs and economic growth (Taylor et al, 2015) in Cebu City.

A "lighthouse" can be built on an island for more journeys leading to its betterment. The purpose of this essay is to describe and evaluate the art ecology of Cebu City and the artists' contexts that define their art profession. This paper first presents the bigger picture of the artistic milieu then proceeds with artist-related factors in art practice. It ends with a discussion on the persistence of art practice in the city.

Dennis E. Montera, Master in Fine Arts, Ph.D. Candidate in Creative Industries Design, Professor of the Fine Arts, College of Communication, Art and Design, University of the Philippines Cebu; Institute of Creative Industries Design, National Cheng Kung University.

Hui-Wen Lin, Ph.D. in Architecture, Associate Professor, Institute of Creative Industries Design, College of Urban Planning and Design, National Cheng Kung University. 


\section{The Art Eco-system of Cebu}

Cebu is an island province geographically located in the central region of the southern Philippine archipelago with a total land area of 5,000 square kilometers. Prior to the arrival of western colonizers, its central location and proximity to neighboring islands has long established Cebu as an ideal trading and cultural hub between local traders and Chinese and Malay merchants as chronicled by Pigafetta who was Ferdinand Magellan’s official scribe when they discovered the Philippines in 1521 (Province of Cebu, 2018).

The arrival of the Christian religion in Cebu City as moral and spiritual ground for Spanish colonization in the sixteenth century ushered in a new era of cultural tradition and creative patronage by the Catholic Church. Early known accounts of professional visual artists in Cebu were borne out of the church's practice to commission painters and sculptors to depict Biblical stories and important religious figures of the Catholic hierarchy as a means of educating people with visual Christian doctrines. This feudal-resembling relationship between artists and the church became the basis of livelihood for many generations of artists that offered artistic services to various dioceses in neighboring islands (Province of Cebu, 2018).

In the years leading to the secularization of art in the late nineteenth century, an artist-to-private-collector system was established among players in the growing middle class and the upper tier market (Guillermo, 2004). Yet, after more than a century where the collector-artist patronage is still the predominant market-base structure, no formal studies were made about Visayan artists, according to one participant who heard Dr. Patrick Flores' lecture during the Natundan: Art Congress of Western Visayas 2014 (personal communication, 2014)—one of the reasons for Cebuano artists to remain in the fringes.

The non-existent art structure in Philippine provinces is largely due to the lack of art-educated ultra-high net worth individuals and lack of galleries and museums in the Philippine countryside (Aljena, 2017). For provincial artists, their collective issues and struggle are also a consequence of the country's dialectic of center and periphery. The "Centre and Periphery" is characterized in terms of Manila-based artists and non-Manila artists and where to a large extent, Philippine contemporary art is almost exclusively sited around a Manila scene (Fairley, 2012). This means that there is no place for the visual arts to thrive in the countryside. However, there are growing communities of sustained visual artist's activities and art markets in Baguio city to the north; and Cebu, Bacolod, Iloilo, and Davao cities to the south, with each having a distinct cultural identity and dynamism.

In the structure of Cebu art, the study prominently recognizes the non-structured practice of so-called gatekeepers of the fine arts such as critics, curators, historians, and art dealers. The dearth of publicly funded art spaces, art museums, strong local gallery-network, and support policies for artists all account for the visual fine arts as inconsequential to the city's cultural identity.

Funding is of the foremost concern as there are limited government subsidy programs in the Philippines for visual artists in general. Aside from the occasional patrons, self-funding by art groups has been the strategy to offset individual costs. Marketing and promotion of art works and exhibitions are channeled through online social media accounts, enabling artists to advertise works-in-progress and recently completed ones in real time. Although online presence does not automatically translate into sales for the artist, a growing perception, whether positive or negative, is immediately formed from people who are able to view and comment on the works. Interestingly enough, the online public perception of the artist's work has occupied the place of traditional 
gatekeepers that are conspicuously scarce. The artist as both producer and distributor is at the forefront of the prevailing realities of the provincial setting.

As reflected in Figure 1 depicting the Art Eco-system Model for Cebu, direct selling and private commissions sans the official trade receipts has been the conventional means of art trade between freelance artists and collectors. Taking the place of publicly funded art spaces are numerous group exhibitions in spaces such as shopping malls, hotel lobbies, and restaurants. Alternative art spaces have contributed to the increase in visibility of visual fine art in the public realm. In the typical primary art market, though relatively young, the few active private galleries operating in the city are admirably playing an important role in growing the distribution and consumption of art in both domestic and international market platforms. Notably, an absence of certified art dealers and auction houses for the secondary art market has considerably left a void in the circulation and increase in value of works by both Cebuano senior-masters and rising young artists. This scenario gives a unique picture of the UNESCO report that in all countries of the Asia-Pacific region, the administration of culture is a responsibility of government (Walker, 1997).

\section{Artist-related Factors in the Art Practice}

The focus of this study is primarily on the condition of fine artists in Cebu—professional visual artists that produce visual art objects distributed in the fine art market of galleries, art fairs, and auction houses; and displayed in art museums (McCarthy et al., 2005). Although the concept of "struggling artist" has been well documented both as myth and reality, only a few artists have chosen to label themselves in such manner in reality (Schneider, 2007). In the Philippines, many of the artists outside the capital region of the Greater-Manila-Area would fall under the categorical description of struggling artist but do not adhere to such negative entitlement.

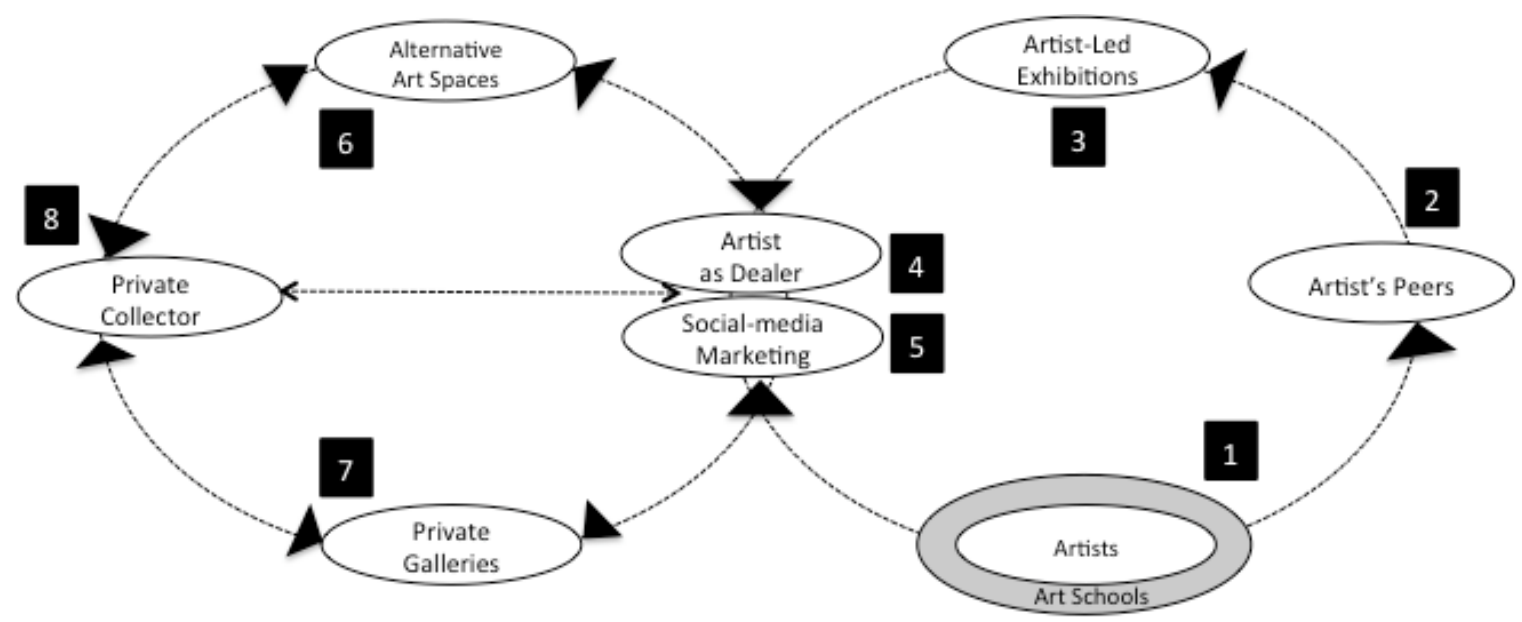

1. Artists gain training from art schools or self-taught

2. Artists attract attention of peers.

3. Artists organize collective exhibitions.

4. Artists present themselves as marketing and sales agent.

5. Artists promote self and art in online portals and social media.

6. Artists mounts exhibitions in alternative art spaces.

7. Gallery notices artist and extends invitation for exhibitions and representation.

8. Private collectors transact with galleries or directly to artists in alternative spaces and social media.

Figure 1. The Art Eco-System Model of Cebu (author's model). 
The majority of artists living and working in Cebu often find themselves unable to work full time in producing works of art. The high costs of living and the daily needs to provide for the immediate family are the main reasons artists seek art-related or non-arts employment. In the Cebu art milieu, this has led to a parallel decrease in the production of new art. The reality also mirrors the city's lack of opportunity for artists in terms of frequency of exposure and market demand in proportion to their population.

A pre-production issue: artists are working in a non-artist workplace. The study has revealed that sixty-three percent of professional artists work at home, meaning, part of their residence also functions as a work studio. Most often, it is the living room, part of the garage, and/or a makeshift roof extension in an open-air area located in the back of the house that suffices as a production area.

Artists have also revealed a scarcity in sourcing quality art materials readily available in the city. With the advent of online shopping of art materials, artists have placed orders in web distributors and pay extra for the shipping fees that deliver domestically in at least three days. More often than not, painters prefer to manufacture their own wooden stretchers, stretching and priming of the canvases prior to the actual painting to save on costs. A similar scenario in workspace, material sourcing, and pre-production issues also apply to sculptors.

The findings disclose that majority of the respondents' art production are mostly dependent on a pre-scheduled artist-led collective exhibition. This reliance on group shows motivates artists to produce one to two pieces per exhibit with the end goal of having a sale. On the other end, individual artist's exhibitions, which produce a series of fifteen to thirty artworks by a single artist, can be found in one or two active art galleries. The galleries, which shoulder most of the expenses for their exhibitions, can only accommodate as many artists in their calendar. A subjective process of selection is extended to potential artists for representation according to a gallery's market orientation and taste.

Non-gallery artists, who comprise the majority of the practitioners market their art, but often with inconsistent results. The direct patronage of collectors benefits mid-career and senior master-artists who have already established their local presence and their artistic style. At the same time, young and emerging artists are finding support from a new generation of collectors on the hunt for less expensive yet quality contemporary art.

The real market challenges for artists in Cebu are the small number of art produced, the lack of variety, and pricing variations. Aside from artists producing less due to time consumed in employment, the effort and costs in planning, mounting, and marketing artist-led exhibitions are timewasting tasks that contribute to lesser production. The apparent similarities in traditional painting styles and content (landscapes, portraits, and genre scenes) and modernist renditions of cubism, abstract expressionism, pop art, and lowbrow street art have not made a substantial impact in the wider Philippine art market, thus, slowing the advancement of Cebu contemporary art in general. On the business side, the more delicate issue of assigning value to artworks based on speculation, pricing trends, and peer pressure has only diminished the selling influence of artists. The inconsistencies in the fair market value of art in Cebu have increased the purchasing power of collectors.

\section{The Persistence of Art Practice}

The majority of the respondents claim that the motivation to create art and the pursuit of an artistic career stems from an inner passion to succeed even without a clear plan to achieve such goals. Albeit romantic and misguided, claims of childhood dreams of becoming an artist persists; thus, following the notion that money from 
art sales is secondary. However, the study suggests that the concept of practicing art in the regions vis-a-vis the active and perceptibly flourishing art-market in the capital is tied to the artists' preference for a better quality of life in the province compared to the higher living costs of the capital city's densely populated urban metropolis. It is, nevertheless, not uncommon for Cebu artists to hold exhibitions and join art competitions in Manila and other parts of the country as a means of extending their networks while maintaining one's base of operations in the island city.

A shared sense of pride in the historicity of place that binds artists who were born and raised in Cebu as well as other artists who migrated from neighboring islands is also evident from their view of cultural identity. For artists, personal-and to some extent-collective identity is equated to religious belief, spoken language, and artistic temperament. The nature of Cebu's strong religiosity as reflected in their festival celebrations in devotion to Catholic icons has deep cultural meaning and high social relevance in the lives of local artists. The city's main festival, the Sinulog, was originally a pre-Hispanic prayer-dance ritual in honor of ancestors and gods in Cebu. The blending of the Catholic religion and folk ritual to become a grand street-dancing festival has annually attracted tourists and employed artists in various fields, making this secular festival the biggest economic driver for cultural heritage tourism and the arts (Cultural Center of the Philippines, 2011).

The native language in Cebu is called Cebuano. Although the official language of the country is Filipino, a standardized version of the native Tagalog language spoken in the capital region and most of the north, Cebuano or Bisaya is among the dominant and significant linguistic and cultural group in southern Philippines (alsintl.com). This sense of disparity between north and south, center and periphery, Tagalog and Cebuano, has heightened the tension of regional self-importance in all aspects of social strata, culture, and governance. It has, in effect, strengthened regional belonging rather than national unity among artists (Philippine Information Agency, 2018).

In the analysis of the nature of Cebu artists, the data would lead to a common presumption that provincial artists are perceived to be laid-back and unassertive. There are certain truths to this presumption if one is looking at benchmarks of production and market turnover only. On the other hand, the study finds that artistic temperament among Cebu artists is just as strong as anywhere in the world. The drives to create art and succeed in an artistic environment without the traditional infrastructure are keeping Cebuano artists on the edge in both creativity and survival. A more appropriate description of creative practitioners in the region is persisting artist.

An entrepreneurial strategy of self-management plays out when artists assume multiple roles in the value chain. The province's non-institutional practice of critics, writers, curators, and logistical art services has forced some artists to learn the tricks of the trade while assuming the role of key cycle players in the art ecology system. The unique perspective of local artists in Cebu puts them in an intermediary position in the discussion between creating art for art's sake and art as commodity. The study's findings acknowledge that concepts in art purity and art's commodification both exist in equilibrium in Cebu's developing ecosystem. The institutional barriers that determine what is good and bad art are mostly left in the hands of artists and collectors.

\section{Conclusion}

More than a century after modern-day visual artists have been documented in the island province Cebu, the conditions of artists are unmistakably bereft of government support in both physical and policy infrastructure. In 
the cultural cycle of art, artists cite inadequacy of workspace, lack of support funding, and daily living costs as the major challenges that affect production of art. Freelance artists find themselves in the dual position of producer and distributor, often maintaining direct personal relations with their markets. Alternative art spaces for a fee, such as malls and hotel lobbies, have become the venue of choice for freelance artists and groups while mainstream art gallery spaces prioritize their represented artists, providing solo exhibitions in the local level and exposing their works in the international stage. The onslaught of social media into all facets of daily life has also proven to be a valuable tool for all types of artists to build on their reputation and market their works. Despite the perceived slow production ratio of artists, the local consumption of art has been steadily growing as evidenced by the number of exhibitions mounted and reports of sales by artist groups and galleries in the previous three years.

In the context of a developing country, the lack of public funds channeled for the administration of culture in governance has contributed to the dearth of national and local policies that focus on artist's careers and their welfare. Cebu has the capacity to improve the conditions of the status of individual artists as key contributors in the creative economy platform; however, these are not part of local city government nor the provincial government's cultural priorities in any long term plan. To be able to improve the artists' situation, a bottom-up approach should grow the art infrastructure through partnerships between artists and private entrepreneurs, and between art platforms and the local community. Among the most important undertakings is developing regulations in the artist-collector relationship, the opening of more dedicated cultural spaces, and investing in community art museums for the mass appreciation of culture and art could provide the groundwork for an organic infrastructure in the province.

Important to note: the future of the professional artist in Cebu will continue to look bleak if policy makers and stakeholders rely upon existing frameworks for its development. Artists in the province see their struggles as part of their environment and they chose to establish artistic careers away from the metropolitan capital for very specific reasons. Their artistic motivation, social identity, and sense of entrepreneurial self-management are intertwiningly linked to the overall quality of life in the island. For the artists themselves, they are too busy earning a living and creating art to care about collective conditions and sustainable eco-systems in the very place they call an island paradise.

\section{References}

Abbings, H. (2002). Why are artists poor? The exceptional economy of arts (pp. 40-55). Amsterdam: Amsterdam University Press. Aljena, A. (2017). Why contemporary artists are starving in Latvia. Journal of Business Management, 10(2), 139-148.

Bilton, C. (2010). Manageable creativity. International Journal of Cultural Policy, 16(3), 255-269.

Cultural Center of the Philippines. (2011). Philippine creative industries mapping: Towards the development of a national strategy. Manila, Philippines: Author.

Fairley, G. (2012). Outside in / Inside out: Observing contemporary Philippine art. First published in thesis eleven: Critical theory and historical sociology (pp. 105-120). United Kingdom: Sage Publishing UK in collaboration with La Trobe University Melbourne.

Guillermo, A. (2004). Cebu, a heritage of art. Philippines: Felipe Y. Liao.

Klamer, A. (1996). The value of culture. On the relationship between economics and arts (pp. 190-205). Amsterdam: Amsterdam University Press.

McCarthy, K., Ondaatje, E. H., Brooks, A., \& Szanto, A. (2005). A portrait of the visual arts: Meeting the challenges of a new era. California: Rand, Santa Monica.

McIntyre, M. (2004). Taste Buds: How to cultivate the art market. England: Arts Council. 
Philippine Information Agency. (2018). Cebu. Retrieved from http://pia.gov.ph/provinces/cebu (July 24, 2018)

Province of Cebu. (2018). Culture and lifestyle. Retrieved from http://www.cebu.gov.ph/about-cebu/culture-and-lifestyle/ (July 24, 2018)

Schneider, E. (2007). Starving for recognition: The representation of struggling artists in America, 1810-1865. USA: Temple University, ProQuest Dissertations Publishing.

Taylor, E., Bonin-Rodriguez, P., \& Essig, L. (2015). Perspectives in arts entrepreneurship, part 1. Artivate: A Journal of Entrepreneurship in the Arts, 4(1), 3-7.

Walker, U. (1997). The survival of the artist: How visual artists live and work. Paris: United Nations Educational, Scientific and Cultural Organization. 